\title{
Espejos trucados: la Secret history or the horrors of Santo Domingo (1808), entre la ficción y la historia antillana ${ }^{1}$
}

\author{
por \\ Loles González-Ripoll \\ Instituto de Historia, CSIC
}

Este artículo centra su atención en un texto publicado en 1808 en Filadelfia que relata los avatares vividos entre 1802 y 1805 por dos mujeres envueltas en los turbulentos años de la revolución de los esclavos en Saint Domingue y los hechos derivados del intento de recuperación del territorio por el ejército francés. Son treinta y dos cartas dirigidas desde Saint Domingue, Cuba y Jamaica en su mayoría a Aaron Burr, polémica figura de la política de Estados Unidos, por Leonora Sansay, mujer de difusa identidad, cuya obra forma ya parte del canon de escritoras del siglo XIX de ese país.

Palabras Clave: Saint-Domingue; Mary Hassal/Leonora Sansay; revolución haitiana; Aaron Burr; Antillas; Cuba.

Trabajando hace más de una década en los fondos de la Rircher Library en la Universidad de Miami me topé con un texto que me interesó desde el principio y que llevaba por título Secret history or the horrors of St. Domingo, in a series of letters written by a lady at cape Francois to colonel Burr, late vicepresident of the United States, principally during the command of general Rochambeau, Philadelfia, Bradford \& Inskeep, R. Carr printer, 1808². En la

\footnotetext{
${ }^{1}$ Trabajo realizado en el marco del Proyecto del Plan Nacional del MINECO (España) HAR2012-37455-C03-03.

2 Otros ejemplares del original de Secret History (1808) en bibliotecas de Estados Unidos como Duke University Rubinstein Library, Pennsylvania State University, University of Pennsylvania o Stony Brook University.
} 
variada tipografía de la portada destacaba el atrayente título de «historia secreta» así como la temática calificada como «los horrores de Santo Domingo» en la época concreta «del mando del general Rochambeau», sucesor del malogrado general Leclerc, el cuñado de Napoleón enviado en 1802 a recuperar la colonia en poder de los ex-esclavos alzados desde 1791. En lugar visible figuraba también el destinatario de la serie de cartas que componen el texto, el «coronel Burr»-Aaron Burr era su nombre completo- consignado aquí como «último vicepresidente de Estados Unidos» (ver ilustración 1).

\section{ILUSTRACIÓN 1}

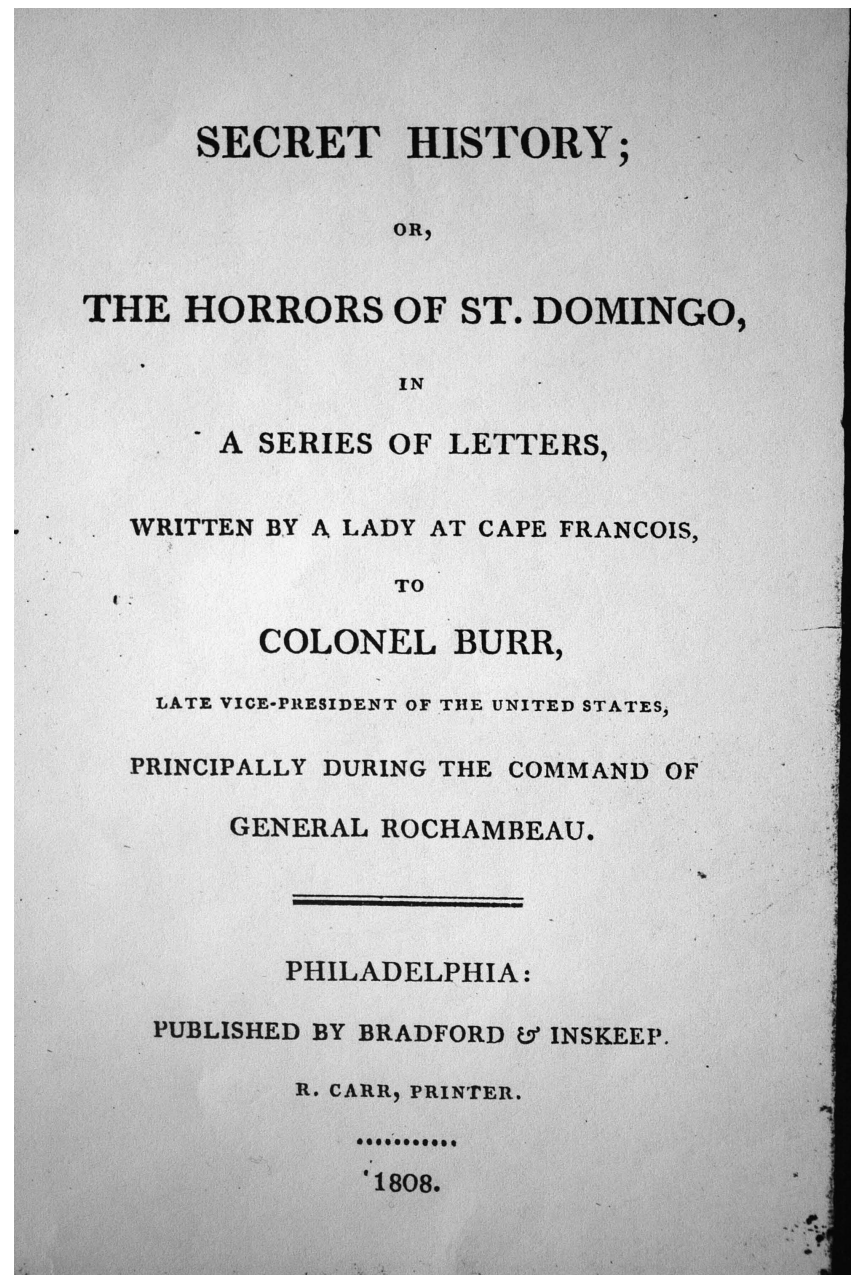


La obra que tenía en mis manos era la primera edición aparecida en 1808 en Filadelfia, en la imprenta de Robert Carr, una figura importante de la comunidad científica del naciente país por sus innovaciones en el campo de la imprenta. En 1815, la esposa de Robert Carr-Ann Bartram- heredó la propiedad donde se hallaba el Jardín Botánico Bartram, el primer jardín de Estados Unidos dedicado a la recepción y cultivo de plantas nativas y exóticas creado en 1728 por John Bartram, cofundador de la American Philosophical Society y padre también del naturalista William Bartram con quien realizó varios viajes de exploración desde Canada al Mississippi. El jardín, aún existente, se situaba cerca de Filadelfia en la zona conocida como Schuylkill River, lugar precisamente donde se crió la misteriosa autora de este texto, la referida por todo dato en el título como «dama en el cabo François», una mujer de múltiples y sucesivas identidades.

Debido al carácter huidizo del texto, a su carácter indefinido y resbaladizo, entre un texto histórico y uno de ficción, rehuí su abordaje en muchas ocasiones aun contando con la reflexión de Hayden White sobre la narrativa como forma de la historia y su identificación con la literatura, también de la difusa frontera entre ambas y de las vinculaciones entre la realidad histórica y la ficción literaria en el sentido de que toda obra literaria bebe de la realidad y toda obra histórica ha de recurrir a la imaginación en la construcción del relato que recupera el pasado ${ }^{3}$.

Secret history es un texto compuesto por treinta y dos cartas escritas por dos hermanas llamadas Mary y Clara, casada con un francés llamado St. Louis: la primera es la principal autora con 29 cartas escritas desde el Caribe a Aaron Burr en Estados Unidos - quien, sin embargo, nunca participó en el intercambio epistolar- y con solo dos cartas dirigidas a la segunda, Clara, que contestó con tres misivas. Las cartas de Mary dirigidas a Aaron Burr tienen origen en tres islas de las Antillas configurando una geografía caribeña específica: primero Mary escribe desde Saint Domingue, después desde Cuba y finalmente desde Jamaica. Por su parte, el intercambio epistolar entre Mary y Clara tiene lugar después de que ambas abandonaran Saint Domingue cuando la primera se halla ya en Kingston (Jamaica) y la segunda en Bayamo (Cuba) tras abandonar a su marido. Más allá del triángulo geográfico caribeño reflejado en los movimientos de las protagonistas y sus cartas, puede observarse la violencia de los lazos matrimoniales en el espejo de la realidad colonial y cómo en su respectivo desafío relaciona los horrores de la disolución matrimonial con la revolución de los esclavos ${ }^{4}$.

\footnotetext{
3 Aurell, 2006.

${ }^{4}$ Burham, 2011.
} 
Las cartas describen los acontecimientos de los que la autora, esa «dama en el cabo François», fue testigo entre 1802 y 1805 en la colonia francesa, convertida en 1804 en la república de Haití tras una violenta revolución y cuando el ejército francés al mando de Leclerc intentó retomar el mando del territorio de Toussaint Louverture y sus hombres. Ella describe su vida bajo la ocupación francesa, así como sus peripecias en Cuba y Jamaica, donde buscaron refugio junto a muchos otros residentes del Santo Domingo francés, un tema profusamente trabajado por especialistas de distintas latitudes como Alain Yacou, Olga Portuondo Zúñiga, Gabriel Debien o María Elena Orozco.

Por otra parte, la propia forma epistolar de un relato en movimiento remite también al género de la literatura de viajes tan común a lo largo de la segunda mitad del siglo XVIII y toda la primera del XIX ya que, como señalan muchos autores, gracias a sus elementos retóricos y estilísticos, la carta parece convertirse en rasgo imprescindible de esta literatura tanto para relatar un viaje real como un viaje imaginado e imaginario ${ }^{5}$. Además, coyunturas históricas concretas en los que proliferaron las emigraciones y los exilios favorecieron la elaboración de cartas de tantos viajeros obligados como es el caso de este texto.

Sin embargo, no estamos ante unas cartas que cumplan las condiciones formales del género epistolar. Aquí no hay fecha aunque sí (aparente) lugar de elaboración de las misivas [Cape Françóis, Barracoa, St. Jago de Cuba, Kingston, Bayam 20 leagues from St. Jago]; las cartas no se abren con un encabezamiento o saludo -a excepción de las intercambiadas entre las dos hermanas- sino que éstos se hallan entrelineados ("we arrived safely here, my dear friend") dado que son dirigidas a un mismo destinatario, -Aaron Burr- $y$, finalmente, tampoco las despedidas están regladas.

Por otra parte, este texto tampoco cumple los requisitos del relato de viaje al uso como narración en primera persona que informa de una manera dinámica, expresiva, vivaz y subjetiva sobre un espacio y sus especificidades ya que, más que un viaje buscado, es una huida forzada por las circunstancias. Unas circunstancias que por su propia naturaleza no permiten la descripción detallada y pausada de paisajes, ambientes, costumbres, aspectos culturales y comportamiento de los habitantes de las zonas visitadas. Lo que sí está presente, como en todo relato viajero de la época, es la libertad del autor -en este caso de la autora- de pensarse a sí misma, de realizar una exploración del yo y construir su propia identidad femenina en medio de la urgencia y la aventura, lo que supone otra singularidad del texto.

Un texto que, dada su procedencia de una pluma femenina, ha estado durante mucho tiempo en la sombra, invisible, olvidado (tópicos acostumbra-

\footnotetext{
${ }^{5}$ Romero Tobar, 2007.
} 
dos en escritos de mujeres) y por su condición de relato menor y anecdótico para la gran historia. En los últimos años, sin embargo, han proliferado los análisis de la Secret history desde multitud de frentes, autores y disciplinas, precisamente por su carácter fronterizo, de híbrido entre la literatura y la historia, el relato de viaje, la construcción de la identidad femenina, etc. Evidentemente, el interés actual por la Secret history se debe también a los cambios historiográficos de los últimos años y al giro cultural que han humanizado la historia poniendo en valor la subjetividad, los pequeños relatos, las narraciones personales y las emociones como construcción individual y colectiva. No sólo porque -como señala Mónica Bolufer- «prestar atención a los sujetos es una deuda moral de los historiadores con los hombres y mujeres del pasado» sino porque -en opinión de Isabel Burdiel- solo así es posible comprender de verdad el cambio histórico ${ }^{6}$.

\section{LA SENDA HISTORIOGRÁFICA}

Al ser Secret history una obra escrita en lengua inglesa por una mujer de Filadelfia, es la academia norteamericana de forma abrumadora la que se ha interesado por desentrañar los muchos significados que parece encerrar. Así, tras su primera edición en 1808 hubo de pasar más de un siglo para la aparición de otra en 1933, también en inglés, y es tres años después, en 1936, cuando se publicó en francés en Haití, en una imprenta de Port-au-Prince con el título de Le Cap Français vu par une américaine, ya sin el anonimato de su autora sino apareciendo el nombre de Mary Hassal ${ }^{7}$. Es interesante constatar también que la traducción a la lengua gala fue realizada por Horace Pauléus-Sannon (1870-1938), historiador, periodista y diplomático haitiano que estudió en París y ya había escribió varios libros sobre el devenir político de su país y acerca de la figura de Toussaint Louverture ${ }^{8}$.

Secret history volvió a publicarse en su idioma original en 1971, en una edición más sintética y directa titulada Secret history, Written by a lady at Cape François to coronel Burr ${ }^{9}$ que consignaba la «triple» autoría de Leonora

${ }^{6}$ Bolufer, 2008: 17. Burdiel, 2000.

${ }^{7}$ Hassal, 1936.

${ }^{8}$ Haïti et le régime parlementaire. Examen de la constitution de 1889 (1898), Un journaliste sous Boyer (1899), Essai Historique sur la Révolution de 1843 (1905), La Guerre de l'Indépendance (1925), Histoire de Toussaint Louverture (1920-1933), etc. Recientemente se han reeditado varios de sus trabajos incluido Le Cap Français vu par une américaine bajo el título Un journaliste sous Boyer, Port-au-Prince, C3 Éditions, 2013.

9 [Leonora Sansay, Mary Hassal, Aaron Burr], 1971. 
Sansay/Mary Hassal y Aaron Burr; y en junio de 1979 se reeditó el texto de 1808 a cargo del Institute for the Study of Human Issues.

Sin embargo, algunos fragmentos de cartas de nuestra protagonista aparecieron en distintos recopilatorios en el siglo $\mathrm{XIX}^{10}$ y su consideración desde la perspectiva feminista fue tempranamente mencionado por Thelma M. Smith en la década de los años cuarenta del siglo veinte ${ }^{11}$.

En los años noventa, algunos y algunas especialistas en literatura «redescubren» la figura de la autora de la Secret history -ahora renombrada Leonora Sansay- y su valor como escritora norteamericana, principalmente Phillip Lapsanky -el primero en ahondar en su vida y escritos-, Joan Dayan -quien reconoció las cualidades literarias de Secret History en su libro Haiti, History, and the Gods (1995) - o Angela Vietto en una recopilación de mujeres escritoras americanas hasta $1820^{12}$.

La primera década del siglo XXI ofrece un panorama abrumador respecto al interés, análisis y difusión del texto en cuestión: en 2006, un artículo de Elizabeth Maddock Dillon, "The secret history of the early american novel: Leonora Sansay and the revolution in Saint Domingue"13; en 2007, Michael J. Drexler, profesor en el departamento de inglés de Bucknell University en Pensilvania, reedita con todo vigor Secret History: or, The Horrors of St. Domingo junto a otro texto Laura que se presume de la misma autora si bien esta vez ya no es definitivamente Mary Hassal sino ya nombrada Leonora Sansay ${ }^{14}$. Esta edición de Drexler, quien señalaba "el interés de entender el significado de esta fascinante novela de intriga caribeña solo recientemente descubierta», se enriquece con otros materiales que contextualizan la obra, entre ellos artículos de prensa, información sobre Haití y documentos históricos como cartas entre Sansay y Aaron Burr, etc., además de artículos posteriores en los que disecciona los muchos significados del texto ${ }^{15}$. En 2008 Jeremy Popkin ${ }^{16}$ recogía la precoz idea de Joan Dayan ${ }^{17}$ situando a Hassal/Sansay en diálogo con otras narrativas de testigos de la revolución y enfatizando la labor de historiadores y, sobre todo, novelistas en el interés despertado en la revolución haitiana gracias a estos textos.

${ }^{10}$ Burdett, 1860, apéndice: 428-437. La carta de Leonora fechada el 6 de mayo de 1818 desde "Cape François. Hayti" debe tener un error de tipografía ya que debería datar de 1803.

11 Smith, 1944.

12 Lapsansky, 1993. Dayan, 1995. Vietto, 1999.

13 Maddock Dillon, 2006.

${ }^{14}$ Drexler, 2007 (reeditado en 2008).

15 Drexler, 2009.

16 Popkin, 2008. Véase también Ianini, 2008.

17 Dayan, 1995. 
Un año más tarde, Gretchen Woertendyke publicaba "Romance to novel: A Secret History" quien subrayaba la trascendencia de la obra más allá de la novela ${ }^{18}$, en 2010 -fecha de otra reedición del texto por Cambridge University Press- Tessie P. Liu ofrecía nuevas perspectivas de análisis al contextualizar la obra en el ámbito del debate sobre raza e insurgencia colonial en el mundo atlántico ${ }^{19}$ mientras Jennifer Van Bergen ${ }^{20}$ se centraba en la vida de su autora.

Además de varias reediciones posteriores del texto de 1808 -en 2011, 2012 y $2013^{21}$, , entre los últimos estudios se encuentran los que persisten en abordar la historia de Leonora Sansay desde la dialéctica de la violencia sobre el cuerpo femenino y la generada por el capitalismo ${ }^{22}$ o en términos de raza, género y clase como el estudio de Melissa Adams-Campbell acerca de las mujeres mulatas y criollas y la competencia por el varón blanco que mejorara su condición, un trabajo que, además, valora la inclusión de Secret history en el canon de la narrativa americana y en tanto que amplia "our discussions of difference beyond the geographical borders of the US and contextualizing her work within a larger revolutionary Atlantic world" 23 .

Efectivamente, merced a su incorporación en el corpus literario de Estados Unidos ${ }^{24}$, la obra de Leonora Sansay/Mary Hassal -antes desconocida y considerada marginal- ha alcanzado mayor trascendencia y su análisis se suma con asiduidad a trabajos más generalistas, no sólo en el ámbito de las letras sino también en el campo histórico; como ejemplos, Encountering Revolution: Haiti and the making of the Early Republic de Ashli White sobre el impacto de la revolución haitiana en Estados Unidos y el devenir de los refugiados de Saint Domingue ${ }^{25}$ o Elzbieta Sklodowska Espejos y espejismos: Haití en el imaginario cubano quien señala la excepcionalidad de un texto por «su valor como fuente de referencia acerca de este episodio particular de la historia de Cuba» [llegada de franceses desde el Saint Domingue revolucionario] escrito por una mujer «a pesar del carácter novelesco de algunos pasajes» ${ }^{26}$. Además, Sklodowska recoge ideas de sus colegas de la academia norteamericana sobre la inspiración caribeña-esclavista de las narraciones

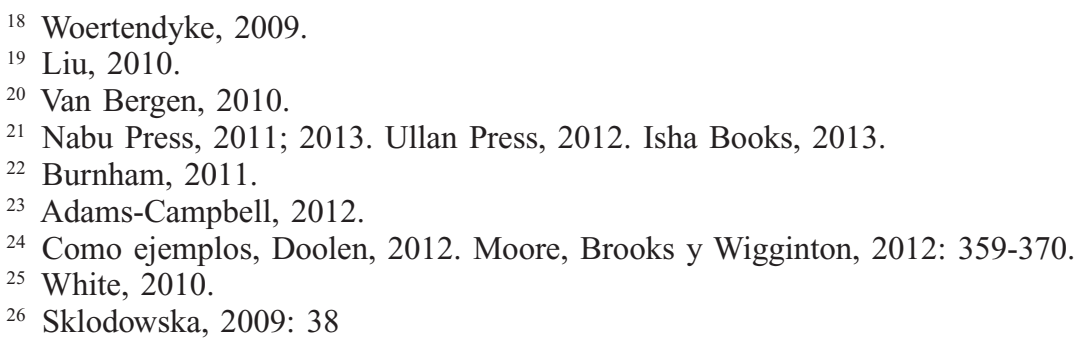


clásicas de la literatura «gótica» anglosajona que incluyen la obra de Mary Hassal/Eleonora Sansay ${ }^{27}$.

En el ámbito iberoamericano hay que destacar a la cubana Luisa Campuzano Sentí por ser la primera hispanohablante en acercarse a Secret History al aludir a la figura y obra de la norteamericana en un libro sobre las mujeres en la historia de España y América Latina ${ }^{28}$.

Finalmente, el creciente interés por desentrañar la vida y la personalidad de la autora de Secret history ha llevado a la apertura de una página en internet ${ }^{29}$ para incorporar toda la información posible sobre ella y también ha tenido eco en la creación artística con la exposición de Camila Huey titulada "Loves of Aaron Burr. Portraits in corsetry \& binding" en la que se recreaban las cartas de Leonora Sansay exhibiendo otros objetos alusivos a su figura para destacar - desde una perspectiva de género- el valor de la lucha individual y colectiva contra cualquier sometimiento ${ }^{30}$.

\section{UNA AUTORA Y VARIAS IDENTIDADES}

Como se desprende del recorrido bibliográfico, seguramente incompleto, donde no hay rastro de ediciones en español ni de acercamientos específicos por parte de especialistas de habla hispana, sí puede concluirse que para la mayoría de los autores la obra Secret history se inserta en el ámbito de la literatura y cómo su abordaje se ha realizado desde variadas perspectivas, cada vez más enriquecedoras, desde el relato de viaje, el género, la raza, la esclavitud, el colonialismo, la cuestión de los sexos, la autobiografía, el paralelismo entre libertad individual y colectiva, el poder y la resistencia, el patriarcado, la autoridad o la obscenidad del capitalismo y su relación con la posesión de tierras y cuerpos femeninos o las conexiones políticas y culturales entre la naciente república de Estados Unidos con la revolución haitiana.

Otro aspecto a destacar es el nutrido número de especialistas que admiran la obra de Mary Hassal/Leonora Sansay, que escriben sobre su trabajo y su figura y se preguntan sobre su vida con un interés que parece provenir de la doble condición de la autora no solo como novelista sino como persona cercana al

27 Ibidem: 35

${ }^{28}$ Campuzano Sentí, 2012.

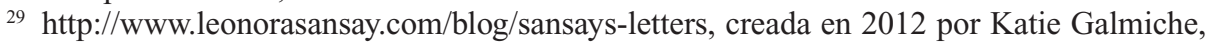
estudiante de Northeastern Illinois University (Chicago). (Fecha de consulta 23/2/2015).

${ }^{30}$ The Morris-Jumel Mansion, 3 de mayo-12 septiembre de 2013. Entrevista con la artista Camila Huey sobre la exposición en www.youtube.com/watch?v=dRTSKdS_7ew (Fecha de consulta 23/2/2015). 
político Aaron Burr, por lo que ahondar en ella y su tiempo alumbra también la enigmática vida de uno de los más tempranos líderes norteamericanos ${ }^{31}$.

Respecto a la autora y al misterio de sus múltiples identidades, Jennifer Van Bergen señalaba en su intento de «reconstruirla» que «nadie sabe quién fue ella realmente ${ }^{32}$ ya que Leonora Sansay parece reinventarse continuamente y haber contribuido a separar las piezas que podrán reconstruir su identidad... Y es que no solo fue Leonora Sansay y también Mary Hassal sino Mme. de Sansée, Mme. D'Auvergne, -nombres que aparecen en fuentes de archivo como «Eleonora Hassel» en el directorio de la ciudad de Filadelfia de 1796- y sus alter egos literarios «Clara» o «Nora Haskel». Ella o todas ellas serían la anónima autora de varios libros (además de Secret history y Laura, Filadelfia, 1809), Zelica: The Creole (Londres, 1820), The Scarlet Handkerchief (Londres, 1823) y The Stranger in Mexico (¿?).

Los datos de que se disponen -realmente una mezcla de fuentes parroquiales, de documentos y correspondencia de Aaron Burr-, además de datos entresacados de las obras de carácter autobiográfico de la propia autora que son a su vez corroborados por fuentes de archivo, señalan que en diciembre de 1773 nació en Filadelfia la niña Honora Davern, hija de Rosa and William Davern, apellido que sería la adaptación al inglés de D'Auvergne aunque también podría ser de origen irlandés. Tras el fallecimiento del padre, la madre se casa en 1779 con otro William, apellidado Hassel quien regentaba una taberna muy conocida en Filadelfia llamada Hassal's Tavern donde se reunían muchos políticos ${ }^{33}$ y la niña de cinco años de nombre Honora o Eleonora Davern pasa a ser Eleonora o Leonora Hassel o Hassal.

El nuevo matrimonio tuvo dos hijos más: William (1783) y Mary (1781) cuyo nombre se ha atribuido a nuestra autora (Mary Hassal). Tras la muerte de los padres, Eleonora Hassel (así aparece registrada en 1796) se ha enamorado de un hombre que muere prematuramente pero a través de quien conocería a Aaron Burr al coincidir ambos precisamente en la taberna de Filadelfia ${ }^{34}$. Burr se convertiría en su amigo, su mentor, su protector, incluso su amante en opinión de algunos, especialmente del que se convertiría en celoso marido de nuestra protagonista, Louis Sansay, un comerciante francés de New York con propiedades en Saint Domingue. De aquí el nombre más canónico de Leonora Sansay con el que la escritora es conocida en la actualidad, si bien también es frecuente encontrar el de Mary Hassal.

\footnotetext{
31 Además del ya citado Drexler, 2009, véanse Drexler y White, 2014. Kennedy, 1999.

32 Van Bergen, 2010.

33 Idem.

${ }^{34}$ Drexler, 2007: 28
} 
El anonimato con el que se publicaron las obras atribuidas a Leonora Sansay tiene que ver con las estrategias propias de ocultación de la escritura femenina en tantos tiempos y lugares, con esa forma singular de «comparecer a la república de las letras» de las féminas sometidas a las características del mercado y a la asunción del recato y la humildad como normas de comportamiento ${ }^{35}$. Esto queda también patente en el prefacio de Secret history firmado por «El Autor» que señala lugar y fecha (Filadelfia, 30 de noviembre de 1807), un breve exordio que es una «captatio benevolentiae» en toda regla en el caso de las mujeres escritoras, una estrategia retórica de minusvalía, una actitud de modestia requerida por la tradición que transcribo en la lengua original por su interés: "I am fearful of having been led into an error by my friends, when taught by them to believe that I could write something which would interest and please; and it was chiefly with a view to ascertain what confidence I might place in their kind assurances on this subject, that I collected and consented, though reluctantly, to the publication of these letters. Should a less partial public give them a favourable reception, and allow them to possess some merit, it would encourage me to endeavour to obtain their further approbation by a little work already planned and in some forwardness" ${ }^{36}$.

Los términos y expresiones utilizadas: «temor», «error», «creer que yo podría escribir algo con interés», «pequeño trabajo» denotan que de una mujer que tomase la pluma se esperaba una actitud reticente a dejarse oír en público y humilde en el reconocimiento y anticipación de sus defectos y carencias, que confesaba dedicar a las letras momentos de ocio robados a sus tareas cotidianas y haber sido instadas por familiares y amigos. Además, Leonora vuelve a ocultarse en el texto al depositar en el personaje de Clara -la hermana de Mary autora de las cartas- sus sentimientos y vivencias. Con los actos de abuso y celos por parte del marido Louis Sansay, quien en la vida y en el papel es abandonado, asistimos a la transformación de Clara-Leonora de victima a liberada, un paralelismo que se ha querido ver en la propia realidad histórica de lo que acontece en Saint Domingue.

Otro factor que contribuye a la invisibilidad de autoras y protagonistas a lo largo de la historia es la importancia que tiende a concederse a los hombres (reales o representados) que figuran en las obras que ellas escriben. Es por ello que en la academia norteamericana hay una profusión de trabajos de carácter histórico en los que se aborda la figura de Leonora Sansay con respecto al receptor de sus cartas Aaron Burr a fin de valorar, primero, la naturaleza de su relación (si fueron amantes, amigos o solamente mentor y discípula) y, así,

\footnotetext{
35 Véase Bolufer, 1999: 207.

36 Secret history, 1808.
} 
llegar a establecer una jerarquía de la conexión entre ambos que otorgue más validez al pensamiento y acción femeninas.

Aaron Burr es una figura todavía polémica en la historia de Estados Unidos; vicepresidente con Thomas Jefferson entre 1801 y 1805, mató en un duelo al también político y economista Alexander Hamilton, encabezó proyectos contra los establecimientos españoles en México y Luisiana (1805-1807) y fue juzgado por traición ${ }^{37}$, hechos sobre los que también existe abundante información en los archivos españoles ${ }^{38}$.

Michael J. Drexler ha relacionado su personalidad y recepción en la política de los nacientes Estados Unidos con la figura del líder de la revolución haitiana Toussaint Louverture por la común admiración y repulsa que ambos fueron capaces de concitar; además, dado que Burr es también presentado como un activo abolicionista cuya presencia política inquietó a los propietarios de esclavos del sur, para Drexler no sería casual que en el título de la obra Secret History el nombre del vicepresidente aparezca destacado a fin de enfatizar un subconsciente colectivo de identificación con un cierto republicanismo negro ${ }^{39}$.

Asimismo, entre la abundante documentación existente de (y sobre) Aaron Burr, es posible encontrar datos fidedignos sobre Leonora ${ }^{40}$. Por ejemplo, de la correspondencia epistolar del político se extrae mucha información sobre la gestación del viaje y del propio texto de Secret History, entre ellos que a principios de 1802 fue enviada a Washington por su marido Louis Sansay para pedir ayuda a Burr a fin de conseguir cartas de recomendación y pasaportes para viajar a Haití y poder reclamar sus propiedades; Burr accedió a la petición como muestra una carta del político a un primo suyo: "Madame Sansay will sail with her husband for St. Domingo (I believe the Cape) in a few days. She is the Lady of whom you may have heard me speak under the name of Leonora, married about two years ago to Mr. Sansay a reputable french merchant, formerly of that island but for some years past resident of New York. I pray you to give M. Sansay a very warm letter of introduction to General Rochambeau. You may speak very highly of her talents, her acquirements and her accomplishments. She speaks and writes french and has more sense and information than all the women to be found in St. Domingo" ${ }^{41}$.

37 Lomask, 1979; 1982. Isenberg, 2007.

38 Véase, entre otros, Archivo General de Indias (AGI), Cuba, 1574, 1708, 1876, etc. Correspondencia reservada del Ministro plenipotenciario de los Estados Unidos con el Capitán General de Cuba y AGI, Santo Domingo, 2600, 2624 y 2647.

39 Drexler y White, 2014.

40 Davis, 1836; 1838. Kline y Wood Ryan, 1983.

41 Kline y Wood Ryan, 1983, II: 702. 
La pareja embarcó a finales de mayo o principios de junio de 1802 hacia Haití y resultado del viaje es el libro publicado en 1808 tras regresar en 1804 a Filadelfia. Lo interesante de esta obra que va más allá de un juego de espejos, de un cruce de géneros, de una búsqueda de identidades y de visiones comparadas es, para el ámbito de historiadores y de especialistas en la cultura y la civilización hispánica, acceder a ella para analizar lo que expresa del mundo antillano, de sus gentes en movimiento y de la forja de una imagen donde el temor está en primer plano y será utilizado interesadamente por muchos ${ }^{42}$.

\section{SECRET HISTORY, HISTORIA DE UN CABOTAJE ANTILLANO}

La huida de «los horrores de Santo Domingo» de nuestra viajera se produjo en la última oleada de refugiados en lo que fue la larga e incesante evacuación de la isla, ya con la derrota definitiva del ejército francés. Como han señalado tantos especialistas, Cuba, por su cercanía, se convirtió en importante lugar de recalada de los que se veían obligados a abandonar Saint Domingue para salvar sus vidas; por ejemplo, en diciembre de 1803 el gobernador de la parte oriental, Sebastián Kindelán informaba de que en los últimos meses habían desembarcado por el puerto de Santiago casi 20.000 personas, además de soldados y oficiales, todos «testigos oculares de lo ocurrido»" ${ }^{43}$ En los dos años siguientes tras la proclamación de la república de Haití y las matanzas desatadas por Jean-Jacques Dessalines continuaron llegando centenares de personas despavoridas que encontraron asilo en las ciudades cubanas de Santiago, Bayamo, Holguín y Baracoa.

Muchos franceses se encontraban desde hacía tiempo en Cuba de forma provisional a la espera de que se restableciera el orden en la colonia. Esta confianza se acrecentó con la llegada del ejército francés al mando de VictorEmmanuel Leclerc, idéntica razón para que el marido de Leonora Sansay pensara en recuperar las propiedades perdidas en 1795 al evacuar la isla precipitadamente, una empresa que se frustró para tantos y que daría lugar a lo que Alain Yacou denominó «el gran éxodo» ${ }^{44}$.

El texto de Secret history surge de este contexto de guerra y desesperación en el que, además, las mujeres serán doblemente víctimas al sufrir -real y metafóricamente- como entes siempre subordinadas a los hombres en la

42 Naranjo Orovio, 2004; 2013.

43 Informe del gobernador Sebastián Kindelán, Santiago de Cuba, 31 de diciembre de 1803, AHN, Estado, leg.6366, caja 2.

${ }^{44}$ Yacou, 2004: 223. 
identificación con el colectivo esclavo tan indefenso y sujeto como ellas. La autora se ocupa de sus congéneres para señalar la posición, ocupaciones, talante y aspiraciones de quienes se convierten en protagonistas y testigos de un periodo turbulento y se centra en el personaje de su hermana Clara -erigida en el alter ego de Mary Hassal/Leonora-, quien aparece casada con un marido al que no soporta y que es bautizado en la ficción como St. Louis. Es, por tanto, la propia historia de Leonora la que queda aquí plasmada ya que utiliza el personaje imaginado de Clara y sus desavenencias conyugales para hacer irrumpir su vida particular en la esfera pública de las letras, actividad que no abandonará una vez regrese a Estados Unidos.

El matrimonio Sansay de la historia (Leonora y Louis) llegaría a Saint Domingue el 7 de junio de 1802, coincidiendo con el día en que el máximo líder de la lucha revolucionaria y jefe máximo de la colonia desde 1800, Toussaint Louverture, tras ser detenido por Leclerc, era embarcado con destino a Francia donde moriría un año después. Louis Sansay encaja dentro del pequeño porcentaje $(6 \%)$ del sector blanco de Saint Domingue que dejó su plantación en manos de Toussaint, se refugió en Nueva York y, tras el nuevo giro dado por Napoleón a la colonia con el restablecimiento de la esclavitud, regresaba para recuperar el patrimonio perdido. Sin embargo, en esta nueva etapa de restauración del régimen francés, la violencia no remitió sino que se agravó bajo el mandato de Donatien Rochambeau, sucesor de Leclerc, quien inició una feroz persecución de los negros de la colonia con el fin de sustituirlos por esclavos recién llegados incontaminados de ideas revolucionarias de libertad e igualdad ${ }^{45}$. El triunfo del colectivo negro y mulato liderado por Dessalines quien declaró la independencia de Haití en enero de 1804, forzó al definitivo «gran éxodo» de los últimos propietarios que habían confiado en la restauración del orden francés en la isla.

Desde el principio, la autora muestra el ansia de poder regresar lo antes posible al continente, a Estados Unidos, su propia patria y la de Mary y Clara, las hermanas del texto. Transmite la sensación de encierro, de prisión, de estar confinada en un lugar muy distinto al de su infancia y juventud en Filadelfia. En la evacuación narrada, la primera recalada fue Cap François (o Françoise o simplemente Le Cap) en el extremo noreste del territorio que en 1803 Dessalines rebautizó como Cap Haitien. Convertido en el último reducto de los franceses, Le Cap es mostrada como una ciudad arruinada, incendiada desde febrero de 1802 por Henri Christopher siguiendo órdenes de Toussaint, con explosiones continuas que habían obligado a mujeres y niños a salir de sus casas y buscar refugio en las montañas...; «no se puede imaginar un pa-

\footnotetext{
${ }^{45}$ Ferrer, 2014: 425.
} 
norama más desolador» ${ }^{46}$, se lee en la primer carta. Sin embargo, en referencia a la devastada ciudad de Cap François, más adelante apreciará lo que queda en pie: edificios públicos como hospitales, los conventos, las calles y plazas, las fuentes o las confortables viviendas que mitigaban el sofocante calor y humedad reinante ${ }^{47}$.

La primera carta también se ocupa de relatar la llegada a Cap François tras una travesía de cuarenta días en barco desde otro punto de la isla y junto a un grupo numeroso de familias francesas que habían dejado Saint Domingue al principio de la revolución pero que habían regresado y se veían entonces en la situación de volver a abandonar para siempre la colonia, ese lugar que «era antes un jardín» ${ }^{48}$ : «muchos de los antiguos habitantes de la isla que emigraron empiezan a pensar que sus esperanzas fueron demasiado optimistas para regresar tan pronto de la tranquilidad del continente» y -continúa la autora respecto a la llegada de la armada francesa- que «muchos de los criollos que habían permanecido en la isla durante el gobierno de Toussaint lamentaban el cambio», que «se quejan y con razón: consideran al ejército enviado en su defensa como opresores que persiguen su destrucción. Sus casas y negros son requisados y ellos son expuestos cada día a nuevas vejaciones» ${ }^{49}$.

Con un país que «está todo en manos de los negros» ${ }^{50}$, la autora se preocupa por la situación política y militar pero también se divierte al percibir las novedades del día a día a pesar de echar de menos los bailes como el marco de sociabilidad al que está acostumbrada. Las mujeres criollas le parecen encantadoras, con una mezcla de Francia y Caribe que cree las hace irresistibles pero, por otro lado, Mary/Leonora Sansay señalará que el criollo «es generoso, hospitalario, espléndido pero vano, inconstante e incapaz de aplicarse seriamente a algo», lo que en las mujeres queda patente cuando recuerdan la «deliciosa» vida que llevaban en la colonia repartida entre el arreglo personal, los baños, la mesa y el amante ${ }^{51}$.

Hay, pues, en las cartas un permanente y continuo cambio de tema saltando de lo general a lo particular, de la reflexión política al comentario más banal. Así, aunque todo lo concerniente a la revolución de los esclavos está presente como marco general de los hechos y se muestran ejemplos concretos de violencia por parte de los negros pero también de despotismo e injusticia

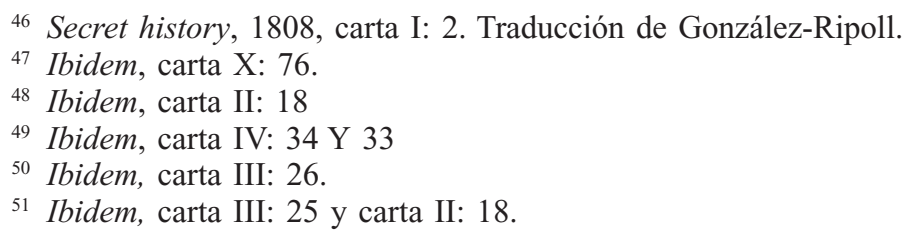

${ }^{51}$ Ibidem, carta III: 25 y carta II: 18 . 
de unos propietarios de vidas y haciendas, todo ello queda en segundo lugar frente a temas más relacionados con la clase social de las protagonistas y su perspectiva de la vida. Dominan los temas de crónica social, los cotilleos, los escándalos e, incluso, algunos con matices sexuales. Es por esto que un especialista ha advertido como el lenguaje de la obra es una muestra de que todo lo relativo a conquistas militares está «sexualizado» y todo lo concerniente a la conquista sexual militarizado ${ }^{52}$.

También se expresan opiniones sobre las principales autoridades de la colonia, especialmente los generales Leclerc - «pequeño, su cara interesante, de salud frágil $\rangle^{53}$-, Boyer y Rochambeau, a quien conoce en un baile y le parece de «cara agradable, boca dulce y sonrisa encantadora pero (...) no presta atención a nada, (...) es bajo y su figura no concuerda con mi idea de que un gran general es siempre un gran hombre» ${ }^{54}$. Rochambeau inicia un galanteo con Clara que provocará en el marido celos con muchas consecuencias.

La siguiente etapa del largo regreso a Estados Unidos será Santiago de Cuba, adonde marchan vía Baracoa en una travesía que duró tres días desde Le Cap «icon qué alegría dejaremos esta tierra de opresiónj» ${ }^{55}$ exclama nuestra autora. Una vez en Baracoa, por primera vez tierra hispana y puerto que se abrió precisamente al comercio internacional en junio de 1803, escribe a Aaron Burr: «aquí estamos, querido amigo, desprovistos de todo lo que poseíamos, en un país extraño, cuya lengua ignoramos y donde, incluso con dinero, nos sería imposible conseguir las cosas a las que estamos acostumbradas (...). Hemos encontrado simpatía por los extranjeros, (...) lo que quizás habríamos conseguido en vano en nuestro propio país y entre nuestra propia gente» ${ }^{56}$. Las dos hermanas fueron presentadas al gobernador ${ }^{57}$ cuya esposa Doña Jacinta insistió en que residieran en su casa mientras se hallaran en una ciudad donde sólo tres casas les parecieron decentes: la de la máxima autoridad y las de un religioso extranjero que les había ayudado al llegar, el padre Phillip, y su hermana viuda.

Sobre la esposa del gobernador se señala que, nacida en La Habana, se casó muy joven y tras el nombramiento de su marido «tuvo que dejar el esplendor de su plaza nativa por este lugar desierto, donde la moda, el buen gusto y la elegancia nunca se han conocido», si bien dejaba claro que algo

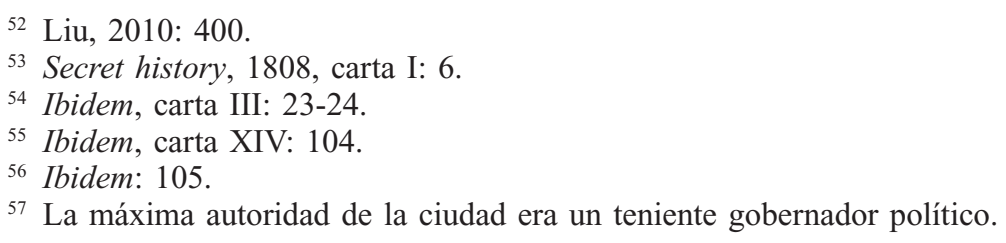


había mejorado con la llegada de franceses exiliados de Saint Domingue ${ }^{58}$. En Baracoa hubieron de esperar un barco que les condujera a Santiago ya que la comunicación terrestre entre ambas poblaciones era inexistente, y cuando por fin se marchan lo hacen con la tristeza de haberse despedido para siempre de buenos amigos y junto a muchas otras personas, en su mayoría mujeres, «jóvenes, bellas y sin recursos, soportando con estoicismo el cambio de suerte» ${ }^{59}$, señala la autora de Secret history quien parte con la intención de permanecer en Santiago junto a su hermana hasta la llegada del marido de ésta.

En Santiago de Cuba, esa «ciudad adormecida» sacudida por la llegada masiva de extranjeros para Alain Yacou ${ }^{60}$ parece que todo va mejor de lo esperado, y tras un mes de estancia las hermanas empiezan a aprender algo de español y disfrutan de diversiones y visitas de una población que «se parece mucho a la de Baracoa» aunque «quizás están un poco más civilizados» ${ }^{61}$. Santiago era la principal ciudad del oriente cubano y llevaba siendo escenario de la llegada masiva de población proveniente de la colonia francesa de Saint Domingue desde 1792. Según las fuentes documentales, entre esa fecha y 1803 el número de inmigrantes pudo llegar a las 30.000 personas, de las que embarcarían hacia Estados Unidos más de 4.000 entre 1803 y $1805^{62}$. Solo en el mes de junio de 1804 llegaron a Santiago catorce embarcaciones y su gobernador Sebastián Kindelán se mostraba angustioso por «la avenida tan extraordinaria e impetuosa de familias con la complicación de los esclavos aunque fueran buenos y fieles» ${ }^{63}$. Como señala Olga Portuondo, en septiembre la situación de la ciudad era muy difícil, había carestía de productos, el alza de los precios era imparable, hasta se especulaba con el agua y las viviendas para tantos recién llegados resultaban insuficientes (en diciembre se calculaba que 332 embarcaciones habían recalado con un total de 18.430 personas sin contar las entradas clandestinas). Kindelán detallaba: «en toda la ciudad no se halla casa alguna desocupada cuando sobre las riberas del mar, bajo de los soportales y en las embarcaciones se ven cada noche abandonados a la intemperie incalculable número de franceses desgraciados que no encuentran una pequeña sombra donde apoyarse» ${ }^{64}$.

\footnotetext{
8 Secret history, 1808, carta XV: 111.

59 Ibidem, carta XVI: 106.

${ }^{60}$ Yacou, 2004: 227.

${ }^{61}$ Secret history, 1808, carta XVII: 119-120.

62 Portuondo Zúñiga, 1993: 68.

${ }^{63}$ Carta al gobernador marqués de Someruelos, Cuba, 30 de junio de 1803, Archivo Nacional de Cuba (ANC), Correspondencia de los Capitanes generales, leg. 63, $\mathrm{n}^{\circ}$ 4. Ibidem: 56.

${ }^{64}$ Ibidem: 59 (notas 59 y 60).
} 
El panorama que pinta nuestra autora no difiere mucho: «nada puede igualar las cosas desagradables de esta ciudad: construida en la pendiente de una colina, las calles están sin empedrar, el reflejo de los rayos del sol en la tierra es horrible y el calor insoportable. El agua es acarreada en mulas desde un río situado a tres millas de distancia y es un artículo muy caro (...) Todo el mundo fuma ${ }^{65}$. A fin de evitar problemas entre la numerosa población congregada y amenizar los momentos de ocio, desde el gobierno se alentó a la organización de toda clase de entretenimiento, desde bailes al levantamiento de un teatro que contó con la colaboración de muchos franceses ${ }^{66}$.

Precisamente prestando atención al contingente galo llegado desde la isla vecina, y especialmente al género femenino, la autora de Secret history señala que las santiagueras «han hecho grandes progresos para mejorar desde que cierto número de franceses han llegado de Santo Domingo. Ellas adelantan a los hombres en refinamiento al menos un siglo, pero [recalca como una obviedad] las mujeres son en todas partes más susceptibles de ser educadas que los reyes de la creación» si bien critica la tendencia de las mujeres cubanas a la intriga, el cotilleo y el rezo del rosario ${ }^{67}$.

De Santiago de Cuba da cuenta de la bella decoración de las casas, de las espléndidas iglesias de la ciudad y del numeroso contingente de religiosos existente, quienes parecen ser de los miembros mejor considerados de la jerarquía social aunque -señala- no es raro ver a algunos darse a la bebida, si bien la mayoría se comporta conforme a las reglas. Señala que ha observado la «abominable costumbre» de que las mujeres en la iglesia cuando se arrodillan o están cansadas cruzan las piernas al estilo de los turcos...y se pregunta con escándalo «¿Desde cuándo esta subversión del orden general?, ¿por qué las mujeres se sientan a los pies de sus esclavos?» Sobre éstos se lamenta de lo harapiento de su vestimenta: "iQué diferentes eran las costumbres en Santo Domingoi [donde] los esclavos domésticos iban vestidos con la más escrupulosa limpieza» ${ }^{68}$. En un permanente ejercicio de análisis por comparación también advierte lo dados a la violencia que le parecen los varones españoles -especialmente en su trato con las mujeres- lo que le lleva a exclamar sobre Estados Unidos y sus gentes «iQué diferente es esto de la pacífica seguridad del país en el que primero respiré y al que ardo en deseos de regresarji ${ }^{69}$.

${ }^{65}$ Secret history, 1808, carta XIX: 135.

${ }^{66}$ Callejas, 1911: 67. En Secret history, 1808 se recoge el cierre del teatro por orden del obispo por «corromper la moral de los habitantes», carta XXIII: 157.

${ }_{67}$ Secret history, 1808, carta XVII: 120.

68 Ibidem: 121-123.

${ }^{69}$ Ibidem, carta XX: 142. 
El contacto con otros refugiados, sus intentos de adaptarse y mejorar ante las dificultades de un lugar como Cuba que «lentamente está saliendo de un estado de barbarie $\rangle^{70}$ lleva a la norteamericana a detallar las desgraciadas historias de tantas mujeres, algunas muy jóvenes, solas o con hijos, enfrentadas a un presente de penalidades e incertidumbres ya que la mayoría ha perdido sus posesiones y con suerte aún les queda algún equipaje después de accidentados viajes. En las crónicas de la ciudad se señala que «muchas señoras francesas, de educación, establecieron sus escuelas de dibujo, bordado, y de su particular idioma, y con este arbitrio reinaba la abundancia en sus casas, otras enseñaban la geografía, la música, el baile, y sacaron excelentes discípulas, (...) otras en el ejercicio del piano, daban sustento a sus hijos, pagaban sus deudas y ponían dinero a interés» ${ }^{71}$.

También es narrada la peripecia del marido de Clara para salir de Saint Domingue, una vez que es consciente del peligro que corren los antiguos propietarios en medio de las luchas incesantes entre las tropas revolucionarias lideradas por Dessalines y el ejército francés. Nuestra autora señala, además, como desencadenante de su marcha la animadversión del general Rochambeau por St. Louis, quien finalmente escapa gracias a la ayuda de un pescador que lo traslada a un navío a punto de zarpar hacia Baracoa, ciudad en la que es auxiliado por los amigos de Mary y Clara, el teniente gobernador y su esposa.

Con la definitiva rendición francesa, siguen llegando barcos desde Le Cap con personas que narran los últimos choques violentos entre los «indígenas» $\mathrm{O}$ negros contra sus enemigos, los blancos residuales. Salpican el texto pequeñas historias de mujeres que permanecieron en Saint Domingue hasta el último momento y cómo la situación más controlada bajo el gobierno de Toussaint fue degradándose hasta perderlo todo y tener suerte de salvar la vida como St. Louis $^{72}$. Éste pronto manifiesta su intención de afincarse en Cuba y comprar una plantación como han hecho otros inmigrantes hasta que la vuelta a St. Domigo sea posible, una idea que persiste en muchos miembros de la colonia francesa en el exterior. Finalmente, nuestra autora anuncia la separación del matrimonio entre St. Louis y Clara, con la huida de ella a Bayamo lejos de una situación de maltrato que trasciende de la relación conyugal a la metáfora de situaciones de dependencia y sujeción tanto de individuos (esclavos, mujeres) como de sociedades (relaciones colonia-metrópoli) así como de su búsqueda de libertad porque «si el marido de Clara la hubiera respetado, ella

\footnotetext{
70 Ibidem: 140.

${ }^{71}$ Callejas, 1911: 68.

72 Secret history, 1808, cartas XXI y XXII.
} 
habría sido uno de los seres humanos más felices pero él echó a perder sus buenas cualidades (...) [y] se convirtió en un tirano» ${ }^{73}$.

Tras un día completo de viaje escribe a Aaron Burr desde Kingston, última escala del largo viaje de vuelta a Estados Unidos y lugar donde encuentra amigos franceses de su estancia en Le Cape hasta que un recién llegado de Cuba le informa del destino de su hermana a la que envía noticias inmediatamente. Así, las últimas cinco cartas del texto tienen la novedad de contener tres extensas misivas de Clara dirigidas a Mary en las que relata la violencia sufrida a manos de su marido y su decisión de abandonarle en el pueblo de El Cobre, donde observa la veneración hacia la Virgen por parte de una mayoría de población mulata que vive pobremente. Libre e instalada en Bayamo, Clara hará comentarios a su hermana de toda índole como que el gobernador es un español irlandés que «habla inglés, (...) [y] es un gran coleccionista de libros» lo que le hace exclamar contenta «jImagínate qué delicia encontrarme con Shakespeare en los campos de Cubaj» ${ }^{74}$.

Con la reunión de las dos hermanas en Kingston y su embarque hacia Filadelfia, concluye esta historia de incesante y obligado cabotaje entre las costas de las Antillas que funde peripecia y emociones individuales con otros aspectos de gran trascendencia en el espacio caribeño y norteamericano y que pueden leerse entre líneas en la última carta de Leonora/Mary a Aaron Burr cuando expresa que Clara está ya «libre del peso de este sentimiento de opresión, que ni el pensamiento de luchas futuras llenas de dificultad y angustia pueden empañar» ${ }^{75}$.

\section{BibLIOGRAFÍA}

Adams-Campbell, Melissa, "Romantic revolutions: Love and violence in Leonora Sansay's Secret History or the horrors of Saint Domingue", Studies in American Fiction, 39(2)/01 (Baltimore, 2012): 125-146.

Aurell, Jaume, "Hayden White y la naturaleza narrativa de la historia", Anuario Filosófico, XXXIX/3 (Pamplona, 2006): 625-648.

Bolufer, Mónica, "Escritura femenina y publicación en el siglo XVIII: de la expresión personal a la 'República de las letras"”, M. Ortega, C. Sánchez y C. Valiente (eds.), Género y ciudadanía: revisiones desde el ámbito privado, Madrid, UAM, 1999: 197-223.

\footnotetext{
73 Ibidem, carta XXXII: 224. St. Louis finalmente regresó a Francia.

${ }^{74}$ Ibidem, carta XXIX: 210.

75 Ibidem, carta XXXII: 225.
} 
Bolufer, Mónica, La vida y la escritura en el siglo XVIII: Inés Joyes: apología de las mujeres, Valencia, Publicacions de la Universitat de Valéncia, 2008.

Burdett, Charles, Margaret Moncrieffe, the first love of Aaron Burr. A romance of the revolution, New York, Derby \& Jackson, 1860.

Burdiel, Isabel, "La dama de blanco: notas sobre la biografía histórica", Isabel Burdiel y Manuel Pérez Ledesma (coords.), Liberales, agitadores y conspiradores. Biografias heterodoxas del siglo XIX, Madrid, Espasa Calpe, 2000: 17-48.

Burnham, Michelle, "Female bodies and capitalista drive: Leonora Sansay's Secret History in transoceanic context", Legacy, 28/2 (Lincoln, 2011): 177-204.

Callejas, José Ma , Historia de Santiago de Cuba, Habana, Impr. La Universal, 1911.

Campuzano Sentí, Luisa, "Memoria y ficción: identidades de género, raza y clase en el espacio colonial cubano: la conexión haitiana", Pilar Pérez-Fuentes Hernández (ed.), Entre dos orillas. Las mujeres en la historia de España y América Latina, Barcelona, Icaria Editorial, 2012: 291-352.

Davis, Matthew L. (ed.), Memoirs of Aaron Burr, 2 vols., New York, Harper \& Brothers, 1836.

Davis, Matthew L. (ed)., The Private Journal of Aaron Burr, During His Residence of Four Years in Europe with Selections from His Correspondence, 2 vols., New York, Harper \& Brothers, 1838 (ed. 1970).

Dayan, Joan, Haiti, History, and the Gods, Berkeley, University of California, 1995.

Doolen, Andy, "Women writers and the early U.S. novel", Dale M. Bauer (ed.), The Cambridge History of American Women's Literature, University of Illinois, UrbanaChampaign, 2012: 119-139.

Drexler, Michael J. (ed.), Secret History; or, The Horrors of St. Domingo and Laura/ Leonora Sansay, Toronto, Broadview Editions, 2007.

Drexler, Michael J., "The displacement of American novel: Imagining Aaron Burr and Haiti in Leonora Sansay's Secret history", Common Place. The Interactive Journal of Early American Life, 9/3 (New York-Fairfax, April 2009). http://www. common-place.org/vol-09/no-03/drexler/2009 (Fecha de consulta 23/2/2015).

Drexler, Michael J. y White, Ed., The traumatic colonel: the founding fathers, slavery and the phantasmatic Aaron Burr, New York, New York University Press, 2014.

Ferrer, Ada, "La revolución haitiana en el Caribe", José Antonio Piqueras (coord.), Historia Comparada de las Antillas, Madrid, Ed. Doce Calles S.L., 2014: 415-443.

Hassal, Mary, Le Cap Français vu par une américaine, Port au Prince, Imprimirie Auguste A. Hereaux, 1936.

[Hassal, Mary] Secret history, Written by a lady at Cape François to coronel Burr, Freeport, New York, Books for Libraries Press, 1971. 
Ianini, Christopher "Secret History; Or, The Horrors of St. Domingo and Laura", Journal of the Early Republic, 28.4 (Philadelphia, Winter 2008): 703-05.

Isenberg, Nancy, Fallen Founder: The Life of Aaron Burr, New York, Viking, 2007.

Kennedy, Robert, Burr, Hamilton, and Jefferson: A Study in Character, Oxford, Oxford University Press, 1999.

Kline, Mary-Jo y Wood Ryan, Joanne, Political Correspondence and Public Papers of Aaron Burr, 2 vols., Princeton, NJ, Princeton University Press, 1983.

Lapsansky, Philip S., "Afro-Americana: Rediscovering Leonora Sansay”, The Annual Report of the Library Company of Philadelphia for the Year 1992, Philadelphia, Library Company of Philadelphia, 1993: 29-46.

Liu, Tessie P., "The secret beyond white patriarchal power: race, gender and freedom in the last days of colonial Saint-Domingue", French Historical Studies, 33/3 (Durham, 2010): 387-416.

Lomask, Milton, Aaron Burr:the years from Princeton to Vice-president 1756-1805, New York, Farrar Straus \& Giroux, 1979.

Lomask, Milton, Aaron Burr: the Conspiracy and years of exile, 1805-1836, New York, Farrar Straus \& Giroux, 1982.

Maddock Dillon, Elizabeth, "The secret history of the early american novel: Leonora Sansay and the revolution in Saint Domingue", Novel, 40/1-2 (Durham, 2006): 77-103.

Moore, Lisa L., Joanna Brooks y Caroline Wigginton, Transatlantic Feminisms in the Age of Revolutions, Oxford, Oxford University Press, 2012.

Naranjo Orovio, Consuelo, "La amenaza haitiana, un miedo interesado. Poder y fomento de la población blanca en Cuba", $\mathrm{M}^{\mathrm{a}}$ Dolores González-Ripoll et al, El rumor de Haití en Cuba. Temor, raza y rebeldía, 1789-1844, Madrid, CSIC, 2004: 82-178.

Naranjo Orovio, Consuelo, "La entronización del miedo; iconos de terror y exclusión en el Caribe tras la revolución de Saint Domingue", Ottmar Ette, Consuelo Naranjo Orovio e Ignacio Montero (eds.), Imaginarios del miedo. Estudios desde la historia, Berlín, Edition Tranvía, Verlag Walter Frey, 2013: 67-90.

Popkin, Jeremy, Facing racial revolution: Eyewitness accounts of the haitian insurrection, Chicago, University of Chicago Press, 2008.

Portuondo Zúñiga, Olga. "La inmigración negra de Saint Domingue en la jurisdicción de Cuba (1798-1801)", Juan Manuel de la Serna (ed.), El Caribe en la encrucijada de su historia, 1780-1840, México D.F., Universidad Nacional Autónoma de México, 1993: 47-74. 
Romero Tobar, Leonardo, "La epistolaridad en los libros de viaje”, José M. Oliver, Clara Curell, Cristina G. Uriarte y Berta Pico (eds.), Escrituras y reescrituras del viaje. Miradas plurales a través del tiempo y de las culturas, Bern, Peter Lang SA, Editorial científica internacional, 2007: 477-487.

Secret History: or, the Horrors of St. Domingo, in a Series of Letters Written by a lady at Cape François to Colonel Burr, late vice-president of the United States, principally during the command of general Rochambeau, Philadelphia, Bradford \& Inskeep, R. Carr printer, 1808.

[Leonora Sansay, Mary Hassal, Aaron Burr] Secret history, Written by a lady at Cape François to colonel Burr, New York, The Black Heritage Library Collection Freeport, Books for Libraries Press, 1971.

Secret History: or, the Horrors of St. Domingo, in a Series of Letters, Cambridge library Collection-Latin American Studies, Cambridge University Press, 2010

Sklodowska, Elzbieta, Espejos y espejismos: Haití en el imaginario cubano, Madrid/ Frankfurt am Main, Iberoamericana/Vervuert, 2009.

Smith, Thelma M., "Feminism in Philadelphia, 1790-1850", The Pennsylvania Magazine of History and Biography, 68.3 (Philadelphia, July 1944): 243-68.

Van Bergen, Jennifer, "Reconstructing Leonora Sansay", Another World Is Possible, 1 (marzo 2010). http://www.a-w-i-p.com/index.php/2010/01/03/reconstructing-leonora-sansay (Fecha de consulta 23/2/2015).

Vietto, American Women Prose Writers to 1820, Carla Mulford, Angela Vietto y Amy Winans (eds.), Dictionary of Literary Biography series, Washington, DC, Bruccoli Clark Layman, vol. 200, 1999.

White, Ashli, Encountering Revolution: Haiti and the making of the Early Republic, Baltimore, Johns Hopkins University Press, 2010.

Woertendyke, Gretchen, "Romance to novel: A Secret History", Narrative, 17/3 (Columbus, October 2009): 255-273.

Yacou, Alain, "La presencia francesa en la isla de Cuba a raíz de la revolución de Saint Domingue (1790 -1809)", Tebeto. En torno a las Antillas hispánicas. Ensayos en homenaje al profesor Paul Estrade, Anexo 5, (Puerto del Rosario, Fuerteventura, 2004): 218-232.

Fecha de recepción: 10 de octubre de 2014.

Fecha de aceptación: 14 de enero de 2015. 


\section{Distorting mirrors: Secret history or the horrors of Santo Domingo (1808), between fiction and history of Antilles}

This article is based on a text entitled Secret history published on 1808 in Philadelphia. There are thirty-two letters that describe the events witnessed by two ladies between 1802 and 1805 in the French colony of St Domingo, which became the Republic of Haiti in 1804 after a fierce revolution. The thirty-two letters are written by Leonora Sansay from the Caribbean (Saint Domingue, Cuba and Jamaica) to Aaron Burr in the United States. The author has been recently incorporated to the US literary canon.

Key words: Saint Domingue; Mary Hassal/Leonora Sansay; Haitian revolution; Aaron Burr; Antilles; Cuba. 